\title{
Optimizing the Cellulose Content of Shea Butter Bark Wood Fibre through Alkali Pretreatment for Composite Application
}

\section{Government Rabboni Mike ${ }^{1, *}$, Thaddaeus Julius ${ }^{2}$, Thompson Edozie Okeke $^{3}$, Ani Amechi Kingsley ${ }^{4}$ and Apake Damina Daniel ${ }^{1}$}

\author{
1Department of Chemical Sciences, Federal University Wukari, P.M.B 1020, Taraba \\ State, Nigeria \\ 2Department of Mathematics and Statistics, Federal Wukari, P.M.B 1020, Taraba State, \\ Nigeria \\ ${ }^{3}$ Department of Civil Engineering, University of Nigeria, Nsukka, Enugu State, Nigeria \\ ${ }^{4}$ Department of Chemical Engineering, Nnamdi Azikiwe University Awka, P.M.B 5025, \\ Anambra State, Nigeria
}

Article Type: Article

Article Citation: Government Rabboni Mike, Thaddaeus Julius, Thompson Edozie Okeke, Ani Amechi Kingsley and Apake Damina Daniel. Optimizing the Cellulose Content of Shea Butter Bark Wood Fibre through Alkali Pretreatment for Composite Application. Indian Journal of Science and Technology. 2020; 13(04), 384-399. D0l: 10.17485/ijst/2020/ v013i04/147288

Received date: September 6, 2019

Accepted date: November 20, 2019

*Author for correspondence: Government Rabboni Mike govt_4real@yahoo.com?Department of Chemical Sciences, Federal University Wukari, P.M.B 1020, Taraba State, Nigeria

\begin{abstract}
Objectives: This study was aimed to optimize the cellulose content (CC) increase with the percentage removal of hemicellulose $(\mathrm{HC})$ and lignin content (LC) of shell butter bark wood fiber (SBBWF) by alkalization process. The truth remains that natural fibers have many uses to be employed in all human activities. The minimization of plant waste is a secret for close economy by effectively converting it to useful ventures. Methods/findings: The SBBWF was inserted in variant solutions for the concentration of sodium hydroxide (CSH) at 3-9 wt\% and the soaking time (ST) for 6-18 $\mathrm{h}$. The SBBWF before and after pretreatment were analyzed through gravimetric method and Fourier transform infra-red (FTIR) to determine its composition and organic substance with corresponding functionality, respectively. The optimization was examined using the central composite design (CCD), an option in response surface methodology (RSM). The results at optimal conditions indicated that the increment in CC with the reduction of HC and LC was $97.9988 \%, 44.5245 \%$, and $45.716 \%$, respectively. The factors at this junction were CSH and ST at $3 \mathrm{wt} \%$ and $18 \mathrm{~h}$, respectively. The $R^{2}$ values of CC, HC and LC had an approximation nearer to 1 . The errors approximated by RSM and experimental readings were $<0.43 \%$. Application: Therefore, the modified SBBWF at this state is potential material in the component of composite manufacturing to be applied in domestic utilization.
\end{abstract}

Keywords: Shell Butter Bark Wood Fiber, SBBWF, Wealth from Waste, Natural Source, Wood Fibre. 


\section{Introduction}

Natural fiber from a wood source has been a potential material as a component for the field of science, engineering and technology in solution to mankind problems. The introduction of fiber from a woody substance in daily activities has geometrically increased globally. However, the huge deposits of these raw materials, lower cost of excavation and preparation, and lighter in terms of density are the reason behind its application in paper, polymer composites, and carbon sheet, building, automobile, and so on [1-11].

The bark from the tree of this wood species, SBBWF is regarded as waste after extracting the timber. In the world at present, technocrats in all area of studies have emphasized to utilize all wastes in the environment with the objectives that these can be translated to useful materials for manufacturers to be applied in both domestic and industrial purpose [12-15]. Regulations and attempt have to be put in place to ensure these wastes are utilized to zip up wastes by recycling and the economy of any nation will improve [16]. In addition, the advantage of land usage in other works of life increases when properly embarks on completely harnessing of wastes for a useful endeavor [17].

Although, SBBWF is basically an agro waste, its compositional part is mainly cellulose. The other major component is hemicellulose, followed by smaller compound identified as lignin and finally with some minute smallest substances in the fiber [18-19]. The percentile of cellulose in the SBBWF is variable depending upon age of the tree, location and plant variety, modification, the yield and period for the growth of the fiber [20].

The de-lignification and reducing some extra constituents of SBBWF such as hemicelluloses and soluble material are essential for its capacity to enhance the cellulosic content for effective application in multiple purposes [21-22]. Therefore, the need for pretreatment of SBBWF is the remedy for reduction of ineffective components. When SBBWF is not pretreated before employing in any industrial processes; it would lead to more water sorption, low adhesion of the fiber when combining with another material such polymer matrix for composite making and poor capability to inculcate stress to another substrate during processing [23]. Furthermore, many methods have been applied for treating the fiber for effectual bonding.

This involves the use of acidification, alkalization, bleaching agent, oxidation and peroxide chemical modifying procedure, etc. By acidifying the bark, denotes soaking of the fiber in either solution of $\mathrm{H}_{2} \mathrm{CO}_{3}, \mathrm{HCl}, \mathrm{HNO}_{3}$ or $\mathrm{H}_{2} \mathrm{SO}_{4}$, etc [24]. The modification of plant fiber with chlorite remains the best option in treating the fiber by bleaching process [12]. In addition, subjecting the fiber through the passage of oxygen gas or in aqueous hydrogen peroxide is another method for activation of cellulosic percentage. Moreover, the simplest method presumes for surface modification of SBBWF is alkalization [22]. Alkalization is the immersion of the SBBWF in a basic solution for the improvement of roughness and cellulose percentage of the fiber. It allows the fiber to activate $\mathrm{OH}$ group which provides intermingling of fiber surface, and enhancing the bonding properties of the SBBWF. The reagents employ for this method are $\mathrm{NaOH}, \mathrm{Ca}(\mathrm{OH})_{2}, \mathrm{KOH}, \mathrm{Mg}(\mathrm{OH})_{2}$, etc [25]. Hence, it is been narrated that bark with a large amount of cellulose gives better stiffness and strength [21].

The mechanism at the period for modification of SBBWF includes: components chain of the fiber loses, solubility and decreasing of undesired compositional compounds in 
the bark and more content of cellulose. Furthermore, the crystalline characteristics are degraded; voids and surface area of bark are tremendously improved [26-28].

The factors that serve as the determinant for the composition of the fiber includes: temperature of modification, the ratio of bark content to solution concentration and pretreated solution time [29].

Later scholars have implemented different reagent to improve the cellulosic component of multiple fibers. These are enlisted: Pterocarpus angolensis (wukwa) [27], pinewood oil palm empty fruit bunch [29-31] corn husk fiber [32], waste betel nut husk fiber [33], Mendong straw [19], rice straw [17], wood pulp [34], century fiber [21], sugar cane basse [35], flask fiber, banana fiber, the typha fiber, rice husk, etc [36-37].

In this research, the optimization of process parameters in alkali-treated novel SBBWF was studied with aim of improving the cellulose, reducing hemicelluloses and lignin content for its functionality in composite making on varieties of industrial applications.

\section{Material and Methods}

\subsection{SBBWF}

The SBBWF (Vitellaria paracloxum) called kadanya in Hausa was sourced in Tella, Taraba, Nigeria. The bark was peeled out from the shell butter wood tree. The bark was dried in 8 hours for 8 weeks in the sun, ground with aid of electric blender Model Vitamix A3500 and sieved employing a 20 mesh size $(850 \mu \mathrm{m})$. The SBBWF of $10 \mathrm{~g}$ was soaked in $\mathrm{NaOH}$ solution at $3 \% \mathrm{wt}, 6 \% \mathrm{wt}$ and $9 \% \mathrm{wt}$ for a time of 6,12 and $18 \mathrm{~h}$ in a different laboratory beaker. The SBBWF was rinsed with distilled water for five times after completion of the absorption time. The SBBWF was placed in an oven at $90^{\circ} \mathrm{C}$ and allowed to dry for $17 \mathrm{~h}$.

\subsection{Evaluation of Cellulose Content}

The SBBWF of $10 \mathrm{~g}(\mathrm{~m})$ was immersed in a mixture of nitric acid (ACS reagent grade), and ethanol solution (ACS grade A1040) for $1 \mathrm{~h}$.

The SBBWF was separated with Whatman filter paper and cleaned with heated water for $50^{\circ} \mathrm{C}$. The solid SBBWF at the top of the filter was maintained at $100^{\circ} \mathrm{C}$ in an oven for a fixed weight $\left(\mathrm{m}_{1}\right)$. The SBBWF cellulose was estimated by applying eq. (1)

$$
\% \text { SBBWF content of cellulose }=\frac{\mathrm{m}_{1}}{\mathrm{~m}} \times \frac{100}{1}
$$

where $\mathrm{m}_{1}$ and $\mathrm{m}$ are the weight of SBBWF before and after oven-dried.

\subsection{Determination of the Hemicellulose Content (Neutral Detergent Fiber Method)}

The SBBWF of $10 \mathrm{~g}$ was refluxed with a solution of $50 \mathrm{ml}$ sodium lauryl sulfate (certified reference material pharmaceutical secondary standard). The SBBWF residue in the mixture was removed out and cleaned in distilled water at $50{ }^{\circ} \mathrm{C}$. The SBBWF residue 
heated in an oven for $8 \mathrm{~h}$ at $100{ }^{\circ} \mathrm{C}$ and weighed $\left(\mathrm{m}_{2}\right)$. The procedure was repeated with 5 $\mathrm{ml}$ of $72 \% \mathrm{w} / \mathrm{w} \mathrm{H}_{2} \mathrm{SO}_{4}$ solution (HPLC grade) and the final residue after oven-dried tagged as $\mathrm{m}_{3}$. The SBBWF hemicelluloses were computed employing eq. (2)

$$
\% \text { SBBWF hemicellose }=\frac{\mathrm{m}_{2-} \mathrm{m}_{3}}{\mathrm{~m}} \times \frac{100}{1}
$$

where $\mathrm{m}_{2}$ and $\mathrm{m}_{3}$ are the residues after oven-dried with base and acid, respectively.

\subsection{Determination of the Lignin Content}

The SBBWF with the same initial weight was fired with $5 \mathrm{ml}$ solution of $72 \% \mathrm{w} / \mathrm{w} \mathrm{H}_{2} \mathrm{SO}_{4}$ for $30 \mathrm{~min}$. The precipitation of SBBWF recorded was rinsed with a mixture of ethanol and de-ionized water at $50^{\circ} \mathrm{C}$. The deposition of SBBWF after filtering and drying in the oven at $105^{\circ} \mathrm{C}$ for $24 \mathrm{~h}$ weighed as $\mathrm{m}_{3}$. The deposit of SBBWF was also moved to another porcelain crucible and heated to $600{ }^{\circ} \mathrm{C}$ at $5 \mathrm{~h}$, finally cooled and weighed as $\mathrm{m}_{4}$. The SBBWF lignin content was evaluated using eq. (3)

$$
\% \text { lignin content }=\frac{\mathrm{m}_{3-} \mathrm{m}_{4}}{\mathrm{~m}} \times \frac{100}{1} .
$$

where $\mathrm{m}_{3}$ and $\mathrm{m}_{4}$ are the residue weight of SBBWF at $105^{\circ} \mathrm{C}$ and $600{ }^{\circ} \mathrm{C}$ after cooling, respectively [38].

\subsection{FTIR Examination of SBBWF}

The FTIR features of SBBWF were examined using a Shimadzu spectrometer Model $8400 \mathrm{~S}$. The SBBWF of $1.5 \mathrm{mg}$ was mixed with $50 \mathrm{mg} \mathrm{KCl}$. The mixture was slotted in the FTIR equipment. After $50 \mathrm{~s}$, the functionality in SBBWF is determined through the corresponding peak in the wavelength by the spectrum as display in the machine.

\subsection{Modeling and Optimization}

The software, design expert version 7.0 was employed using RSM of CCD. The faced center option of CCD was used to input the response and factors resulting in 13 experimental runs. The analysis of variance was structured to maintain a $95 \%$ confidence level.

\section{Result and Discussions}

Figure 1(a-b) illustrates the FTIR of unmodified and pre-treated SBBWF, respectively. As noticed in Figure 1(a), the occurrence of $\mathrm{OH}$ and $\mathrm{C}-\mathrm{H}$ bond can be stared at $3365.1 \mathrm{~cm}^{-1}$ and 2922.2 at $81.58 \%$ and $83.574 \%$ in transmittance corresponding to alcohol and alkane, respectively. These were observed in Figure 1(b) at $3309.9 \mathrm{~cm}^{-1}(\mathrm{OH})$ and emergence of the bond $\mathrm{C}-\mathrm{H}$ with an improvement of the percentile transmittance at $88.925 \%$ and 


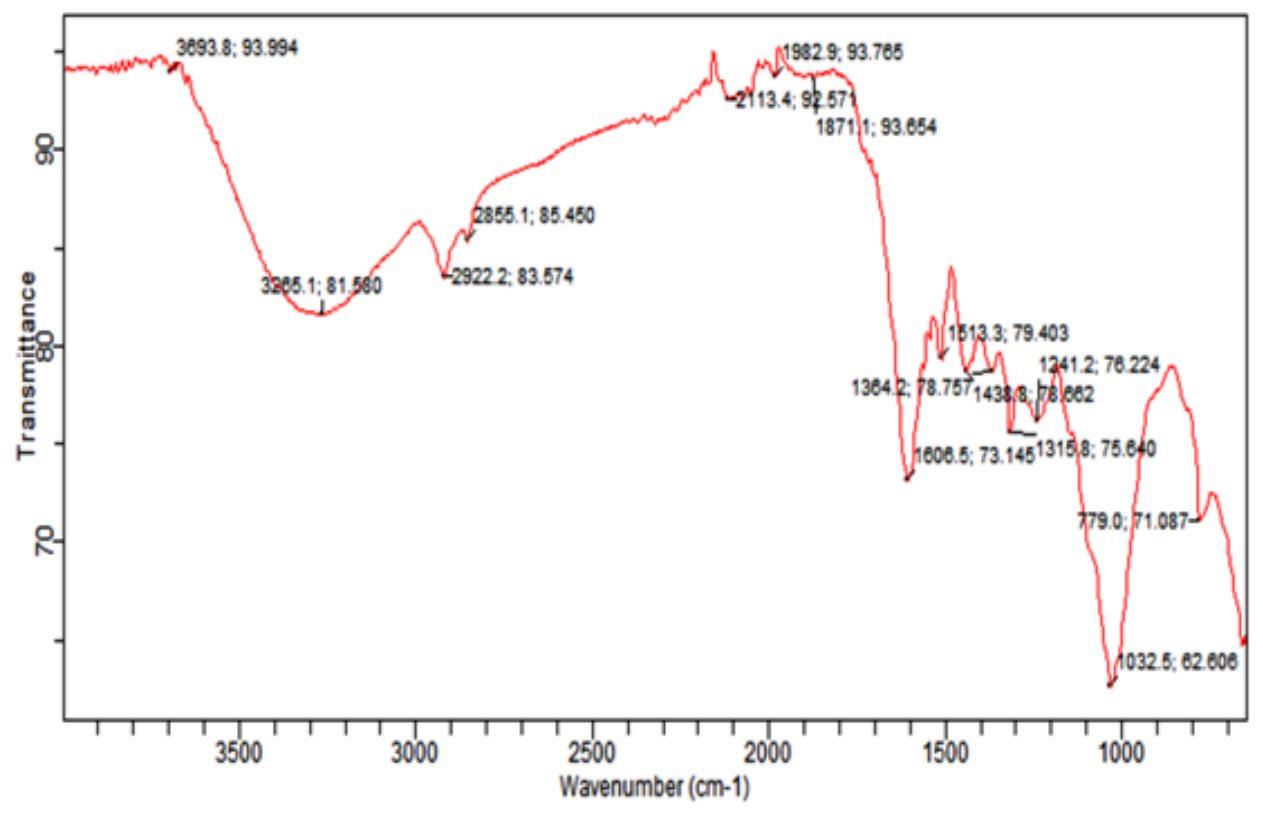

a

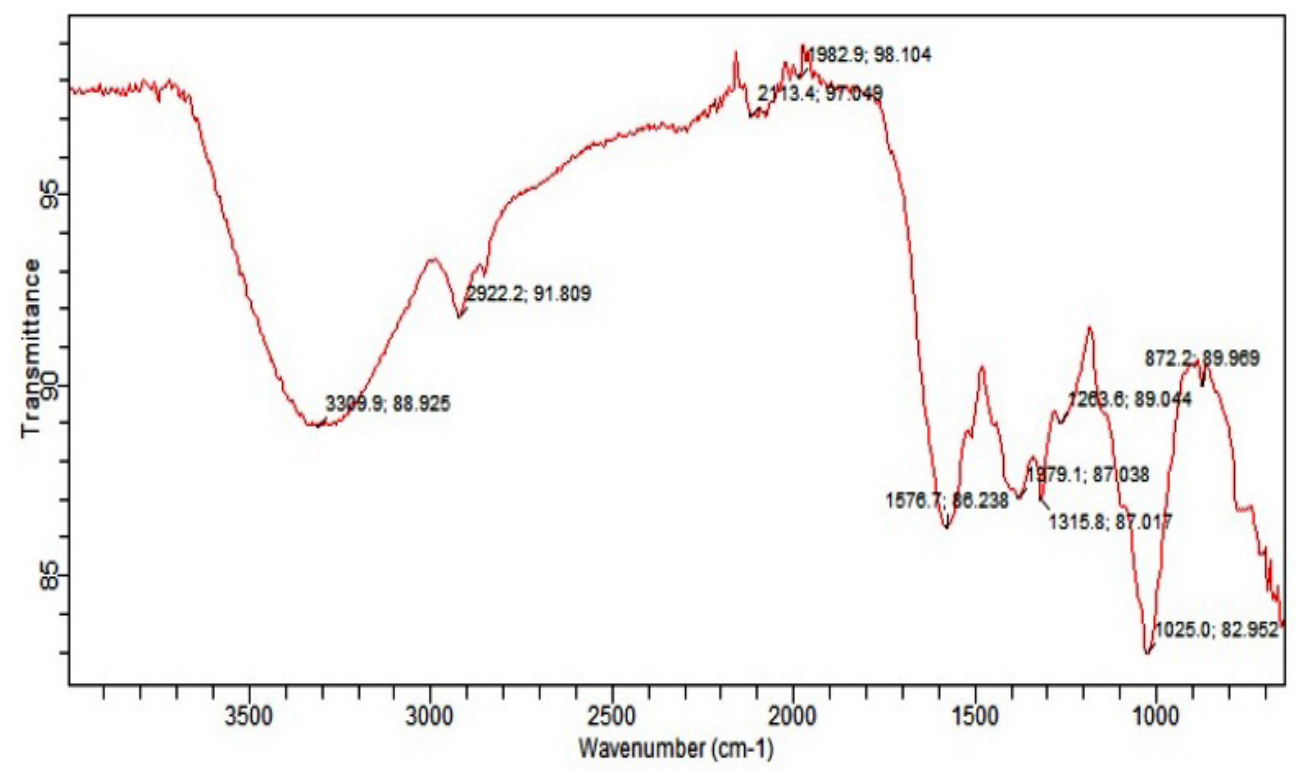

b

FIGURE 1. FTIR spectra of SBBWF for (a) unmodified (b) modified.

91.908\% when immersed in $\mathrm{NaOH}$ solution, respectively. The $\mathrm{NO}_{2}$ aromatic compound was found in Figure 1(a) at $1513.3 \mathrm{~cm}^{-1}$ at $76.224 \%$. After pre-treatment as narrated in Figure $1(\mathrm{~b})$, the $\mathrm{C}-\mathrm{N}$ and $\mathrm{C}=\mathrm{C}$ bonds of pyridine emerged at $1576.7 \mathrm{~cm}^{-1}$ at $86.238 \%$. The observation is due to the activation of SBBWF with $\mathrm{OH}$ ions which improve the focal content of SBBWF and reducing unwanted substance in the fiber after treatment. In 
conclusion, the enhancement of the transmitting percentile and formation new substance after alkali modification of SBBWF exhibited an increment in CC and removal of HC and LC, respectively as reported [39].

Table 1 indicates the design matrix for the composition of modified SBBWF. As shown in Table 1, the combination of the variation of CSH and ST to yield the increase in CC and the percentile reduction of $\mathrm{HC}$ and LC after pre-treatment. The combined CSH, ST, and the corresponding improvement in $\mathrm{CC}$, the $\mathrm{HC}$ and LC removal formed the empirical models whose equations were applied to forecast the enhancement of main compositional constituent of SBBWF. The regression equations for CC, HC, and LC are stated using eq. 4 , eq. 5 , and eq. 6 , respectively.

$$
C C=52.62-36.6 C S H+5.52 S T-1.42 C S H S T+2.59 C_{S H} H^{2}-0.75 S T^{2}
$$

$$
\begin{aligned}
& \mathrm{HC}=-3.49306+8.1707 \mathrm{CSH}+2.27124 \mathrm{ST}-0.085389 \mathrm{CSH} \mathrm{ST}-0.47544 \mathrm{CSH}^{2}-0.026194 \mathrm{ST}^{2} \\
& L C=+72.05883-14.93440 \mathrm{CSH}-5.96737 S T+0.26747 \mathrm{CSH} S T+1.33251 \mathrm{CSH}^{2}+0.30690 \mathrm{ST}^{2}
\end{aligned}
$$

The ANOVA for the chemical constituent of chemically modified SBBWF is mentioned in Table 2. The model for CC, HC, and LC was thoroughly significant. In addition, the coefficient of the variables, $\mathrm{CSH}, \mathrm{ST}, \mathrm{CSH}^{*} \mathrm{ST}, \mathrm{CST}^{2}$, and $\mathrm{ST}^{2}$ for CC, $\mathrm{HC}$, and $\mathrm{LC}$ sustained probability value $<0.042$. The $R^{2}$ of CC, HC and LC retained decimal values close to 1 . The predicated $R^{2}$ showing related values of the adjusted $R^{2}$. Moreover, the differentials of both $R^{2}$ were minimal. These indicate a complete increase in CC, high experimental overhauling of $\mathrm{HC}$ and $\mathrm{LC}$ in the SBBWF by $\mathrm{NaOH}$ modification process. With the high values of $R^{2}$ for CC, $\mathrm{HC}$, and LC; these mean that the precision and reliability of the study were carefully carried out. The results for CC, HC, and LC were the familiar trends by authors in the research area [40-44].

TABLE 1. Design matrix for the composition of modified SBBWF

\begin{tabular}{lccccc}
\hline & \multicolumn{3}{c}{ Factors } & \multicolumn{3}{c}{ Responses } \\
\cline { 2 - 6 } Run & CSH & ST & CC & HC & LC \\
\cline { 2 - 6 } & $\%$ & h & \% & \% & \% \\
\hline 1 & 6 & 12 & 52.788 & 45.72 & 21.326 \\
2 & 6 & 12 & 52.788 & 45.72 & 21.326 \\
3 & 9 & 18 & 21.959 & 50.5 & 79.904 \\
4 & 6 & 12 & 52.788 & 45.72 & 21.326 \\
5 & 6 & 12 & 52.788 & 45.72 & 21.326 \\
6 & 3 & 12 & 91.357 & 37.155 & 23.745 \\
7 & 3 & 6 & 84.55 & 27.407 & 17.989 \\
8 & 6 & 12 & 52.788 & 45.72 & 21.326 \\
9 & 9 & 6 & 14.146 & 39.056 & 33.883 \\
10 & 9 & 12 & 18.221 & 45.938 & 49.475 \\
11 & 6 & 18 & 57.362 & 50.709 & 53.331 \\
12 & 3 & 18 & 98.029 & 44.999 & 44.752 \\
13 & 6 & 6 & 45.53 & 39.056 & 18.001 \\
\hline
\end{tabular}


Optimizing the Cellulose Content of Shea Butter Bark Wood Fibre through Alkali Pretreatment for Composite Application

TABLE 2. ANOVA of compositional modified SBBWF

\begin{tabular}{|c|c|c|c|c|c|c|}
\hline Source & $\begin{array}{l}\text { Sum of } \\
\text { squares }\end{array}$ & df & Mean square & $F$ value & $\begin{array}{l}p \text {-value } \\
\text { Prob }>F\end{array}$ & \\
\hline \multicolumn{7}{|c|}{$\mathrm{CC}$} \\
\hline Model & 8247.719 & 5 & 1649.544 & 7669.797 & $<0.0001$ & Significant \\
\hline A CSH & 8038.092 & 1 & 8038.092 & 37374.29 & $<0.0001$ & \\
\hline B-ST & 182.8666 & 1 & 182.8666 & 850.265 & $<0.0001$ & \\
\hline $\mathrm{AB}$ & 8.025889 & 1 & 8.025889 & 37.31755 & 0.0005 & \\
\hline $\mathrm{A}^{\wedge} 2$ & 18.55428 & 1 & 18.55428 & 86.27084 & $<0.0001$ & \\
\hline $\mathrm{B}^{\wedge} 2$ & 1.558146 & 1 & 1.558146 & 7.244831 & 0.0310 & \\
\hline Residual & 1.50549 & 7 & 0.21507 & & & \\
\hline Lack of fit & 1.50549 & 3 & 0.50183 & & & \\
\hline Pure error & 0 & 4 & 0 & & & \\
\hline Cor total & 8249.225 & 12 & & & & \\
\hline Std. dev. & 0.463756 & & R-squared & 0.999817 & & \\
\hline \multirow[t]{2}{*}{ Mean } & 53.46877 & & Adj R-squared & 0.999687 & & \\
\hline & & & $\begin{array}{r}\text { Pred R-squared } \\
\text { HC }\end{array}$ & 0.998563 & & \\
\hline Model & 469.4282 & 5 & 93.88565 & 236.1121 & $<0.0001$ & Significant \\
\hline $\mathrm{A}-\mathrm{CSH}$ & 112.0867 & 1 & 112.0867 & 281.8858 & $<0.0001$ & \\
\hline B-ST & 275.9325 & 1 & 275.9325 & 693.9397 & $<0.0001$ & \\
\hline $\mathrm{AB}$ & 9.449476 & 1 & 9.449476 & 23.76439 & 0.0018 & \\
\hline $\mathrm{A}^{\wedge} 2$ & 50.56963 & 1 & 50.56963 & 127.1771 & $<0.0001$ & \\
\hline $\mathrm{B}^{\wedge} 2$ & 2.455931 & 1 & 2.455931 & 6.176397 & 0.0419 & \\
\hline Residual & 2.783422 & 7 & 0.397632 & & & \\
\hline Lack of fit & 2.783422 & 3 & 0.927807 & & & \\
\hline Pure error & 0 & 4 & 0 & & & \\
\hline Cor total & 472.2117 & 12 & & & & \\
\hline Std. dev. & 0.63058 & & R-squared & 0.994106 & & \\
\hline \multirow[t]{2}{*}{ Mean } & 43.34 & & Adj R-squared & 0.989895 & & \\
\hline & & & $\begin{array}{c}\text { Pred R-squared } \\
\text { LC }\end{array}$ & 0.94022 & & \\
\hline Model & 4208.439 & 5 & 841.6878 & 181.5719 & $<0.0001$ & Significant \\
\hline A-CSH & 982.4257 & 1 & 982.4257 & 211.9324 & $<0.0001$ & \\
\hline B-ST & 1948.106 & 1 & 1948.106 & 420.2524 & $<0.0001$ & \\
\hline $\mathrm{AB}$ & 92.71764 & 1 & 92.71764 & 20.00138 & 0.0029 & \\
\hline$A^{\wedge} 2$ & 397.2207 & 1 & 397.2207 & 85.68987 & $<0.0001$ & \\
\hline $\mathrm{B}^{\wedge} 2$ & 337.1471 & 1 & 337.1471 & 72.73057 & $<0.0001$ & \\
\hline Residual & 32.44894 & 7 & 4.635562 & & & \\
\hline Lack of fit & 32.44894 & 3 & 10.81631 & & & \\
\hline Pure error & 0 & 4 & 0 & & & \\
\hline Cor total & 4240.888 & 12 & & & & \\
\hline Std. dev. & 2.153036 & & R-squared & 0.992349 & & \\
\hline \multirow[t]{2}{*}{ Mean } & 32.90077 & & Adj R-squared & 0.986883 & & \\
\hline & & & Pred R-Squared & 0.947539 & & \\
\hline
\end{tabular}

Figure 2(a-c) pictures the graph of real experimental values against the RSM values for the improvement in the composition of the treated SBBWF for CC, HC, and LC, respectively. From Figure 2(a), (b), and (c), it was captured that the plotted points coincided with the diagonal line for CC, $\mathrm{HC}$ and LC, respectively. This assertion indicated that the models for CC, HC, and LC using RSM gave better forecast on the upgrading of the CC, 

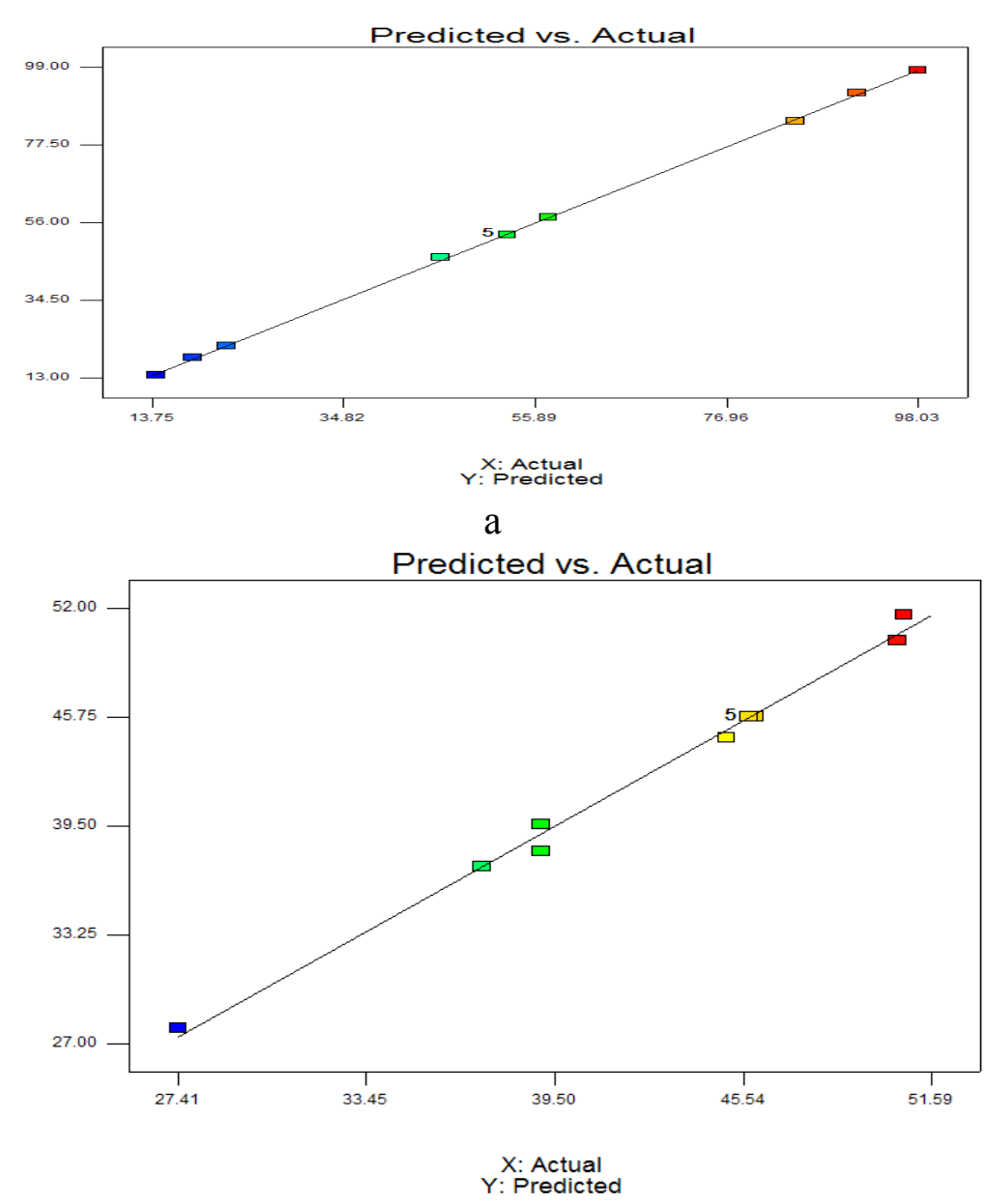

$\mathrm{b}$

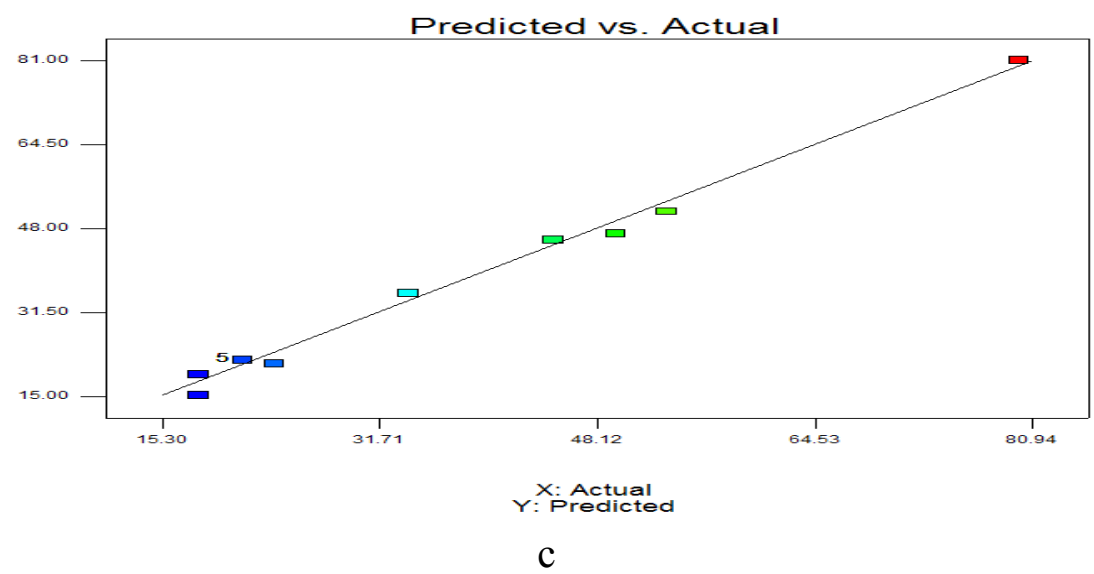

FIGURE 2. Actual versus predicated plots for (a) CC (b) HC (c) LC of modified SBBWF. 
and degrading of HC and LC by treated SBBWF, respectively. The similarity of the study has been emphasized by earlier workers [44-47].

From Figure 3(a) and (b) presents a graphical description of the contour and 3-D surface of the increase in pre-treated SBBWF CC, respectively. It was depicted that the optimum prediction of CC increment was seen in the reddish region of the contour at $97.9966 \%$ in Figure 3(a). However, the maximum CC corresponded to CSH at 3\% wt and ST of $18 \mathrm{~h}$.

In addition, in Figure 3(b), for constant ST, the CC reduced at high CSH increase. This phenomenon is due to a higher $\mathrm{CSH}$, the cellulosic constituent of SBBWF is shattered. Meanwhile, at steady CSH, the CC inclined at more ST of SBBWF in NaOH. The existence of this fact is as a result of longer ST yields more CC of modified SBBWF. These observed facts were in conformity with previous reporters [48].

The HC removal of pre-treated SBBWF contour and 3-D surface plots is presented in Figure 4(a) and (b), respectively. Moreover, the optimum HC removal was traced at the yellowish vicinity at the prediction of $44.539 \%$ as shown in Figure $4(\mathrm{a})$. At this point of optimum $\mathrm{HC}$, the $\mathrm{CSH}$ and ST were cited at $3 \mathrm{wt} \%$ and $18 \mathrm{~h}$, respectively.

With respect to Figure 4(b), the HC removal was found to increase with the increment in CSH at steady ST. This is attributed to the modification of SBBWF enhances the elimination of HC. In addition, at fixed CST, the HC removal capacity was upgraded during higher ST. Similar expectations were recorded by earlier scholarly articles [49].

Figure 5(a) and (b) portrays the removal of LC in treated SBBWF contour and 3-D surface plots, respectively. As shown in Figure 5(a), the optimum prediction of LC removal in treated SBBWF is situated in the green region of the contour plot at $45.716 \%$. The CSH and ST were domiciled at $3 \mathrm{wt} \%$ and $18 \mathrm{~h}$, respectively.

It was traced in Figure 5(b) at constant CSH, the LC removal amplified at more ST. This trend in HC was observed in LC. When ST is steady, the LC removal increases after absorbing in more $\mathrm{CSH}$. The reason behind the phenomenon is that during immersion of SBBWF in $\mathrm{NaOH}$, most of the undesirable component has been eliminated making the fiber to boost its intermingle ability and the cellulosic amount due to activation of the fiber surface by $\mathrm{OH}$ radicals. Preceding scholarly works have obtained a close outcome [50-51].

Figure 6 displays the overlay plot for enhancing the CC, the reduction of HC and LC from treated SBBWF. From the above plot, the optimal CC, HC, and LC of the pre-treated SBBWF occurred at $97.9988 \%, 44.5245 \%$, and $45.718 \%$, respectively. These coincided with $\mathrm{CSH}$ and ST of SBBWF at $3 \mathrm{wt} \%$ and $18 \mathrm{~h}$, respectively. Therefore, the SBBWF at this pretreating condition is required for composite production in domestics use.

Table 3 presents the comparison of the predicted CC, HC, and LC for modified SBBWF at the optimal situation. From the observation in Table 3, the percentage relativities between CC, HC, and LC of SBBWF chemically modified were barely $<0.43 \%$. This is a significant affirmation that the RSM software forecasted the experimental data with lower errors.

\section{Conclusion}

The work presents SBBWF as novel and low cost material which can be applied in the field of composite engineering. The process parameters; CSH and ST were able to show 


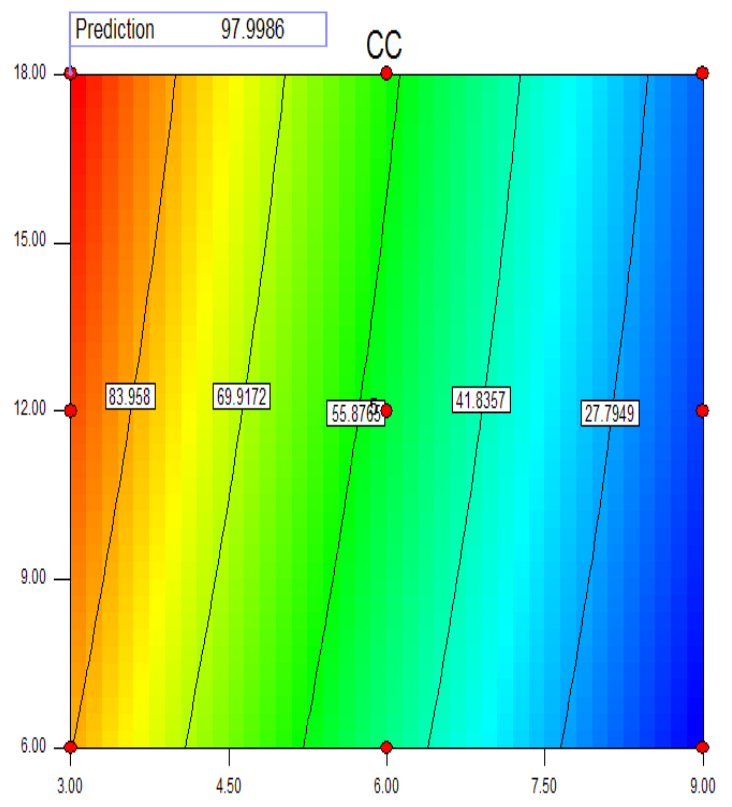

X1: A: CSH

X2: B: ST

a

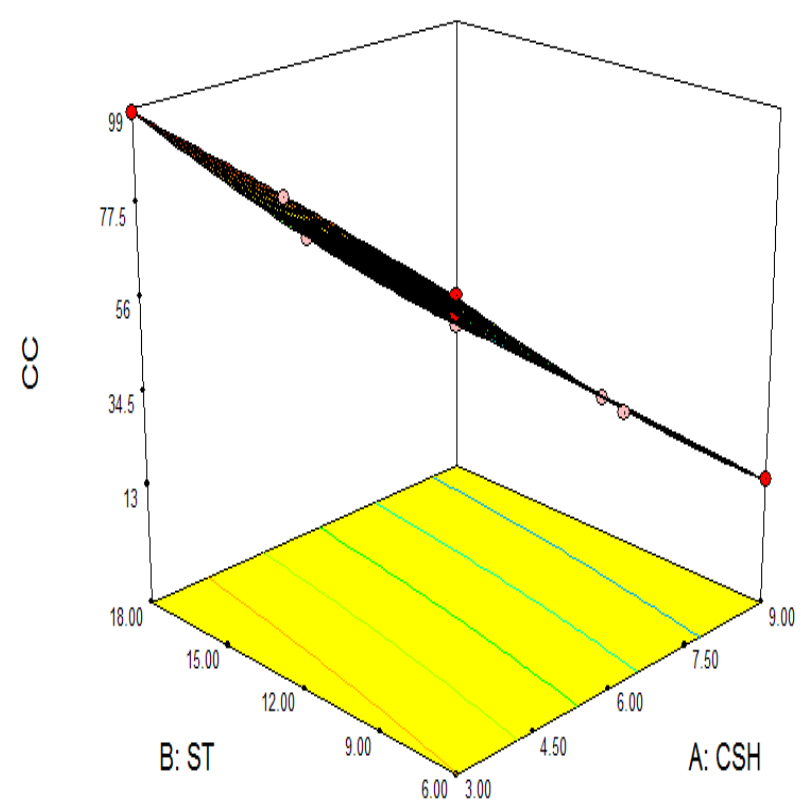

b

FIGURE 3. The enhanced CC of pre-treated SBBWF graph for (a) contour (b) 3-D surface. 
Optimizing the Cellulose Content of Shea Butter Bark Wood Fibre through Alkali Pretreatment for Composite Application

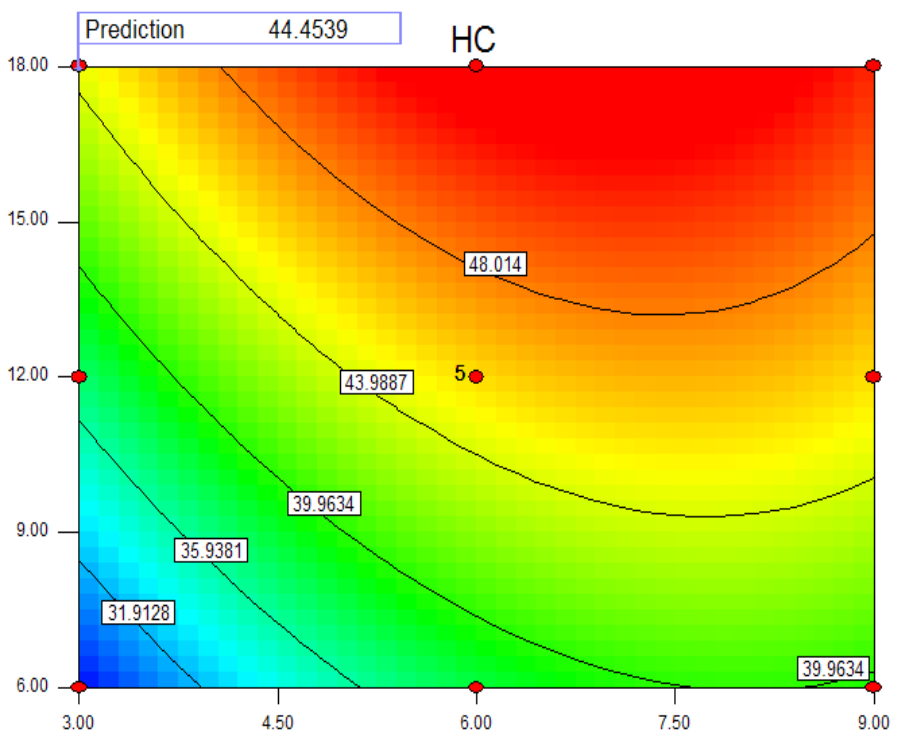

$\mathrm{X} 1: \mathrm{A}: \mathrm{CSH}$

X2: B: ST

a

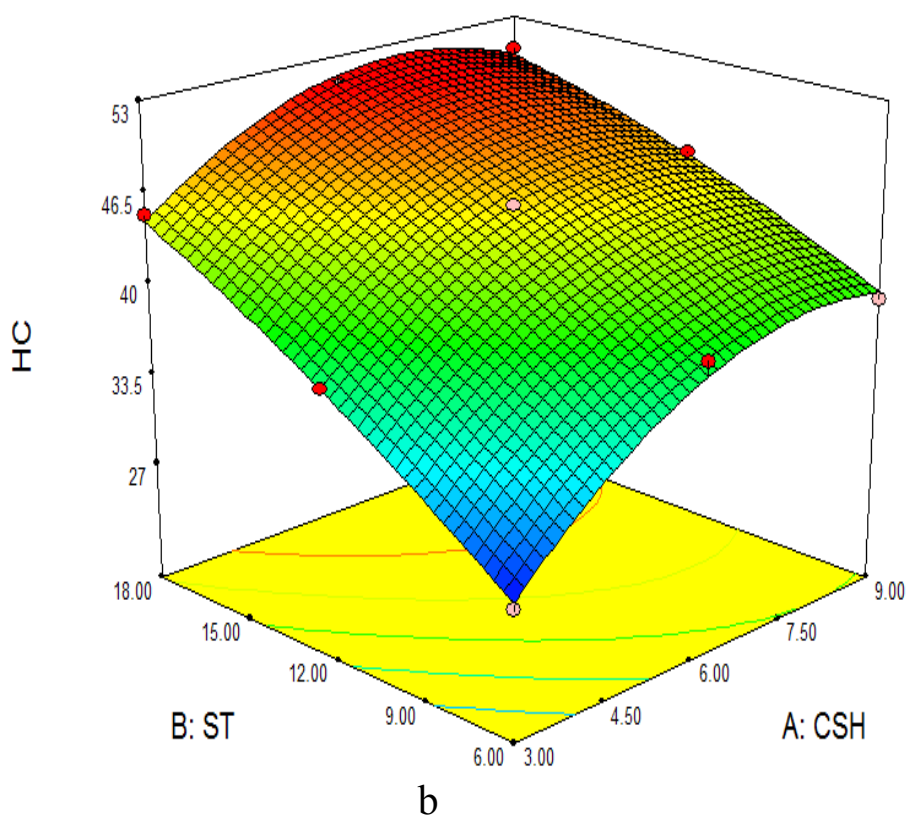

FIGURE 4. The percentage removal of HC in pre-treated SBBWF for (a) contour (b) 3-D surface. 

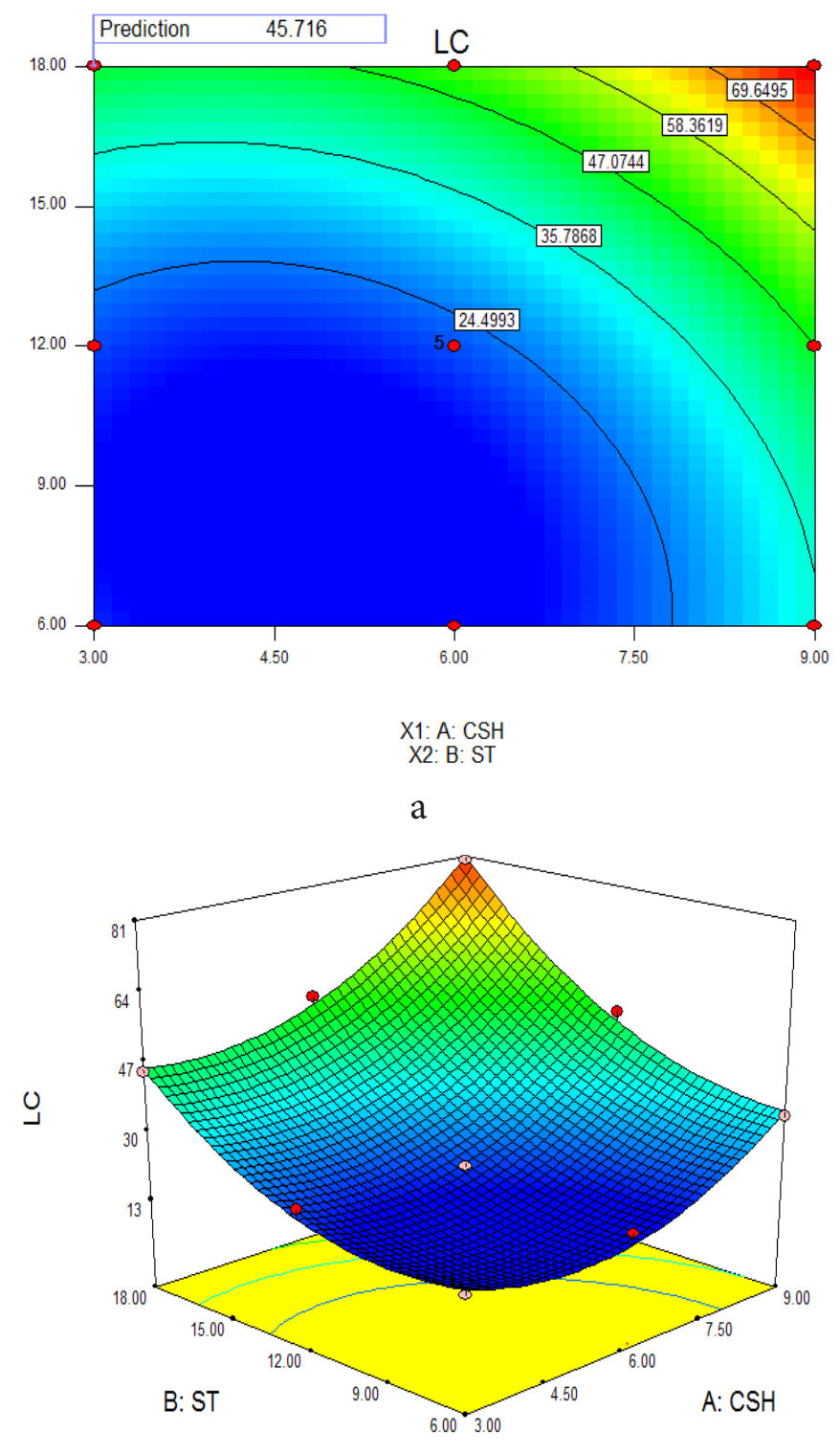

b

FIGURE 5. The percentage removal of LC in pre-treated SBBWF for (a) contour (b) 3-D surface.

more impact on the composition of SBBWF. The pre -treatement process of SBBWF was able to enhance the CC and facilitated the HC and LC removal. FTIR spectra were able to show the main difference before and after treatment. The RSM was able to forecast the CC, HC and LC with minimal error. The data obtained from the estimated values of RSM prediction of pre-treated SBBWF shows that it is a promising material for reinforcement in composite application. 


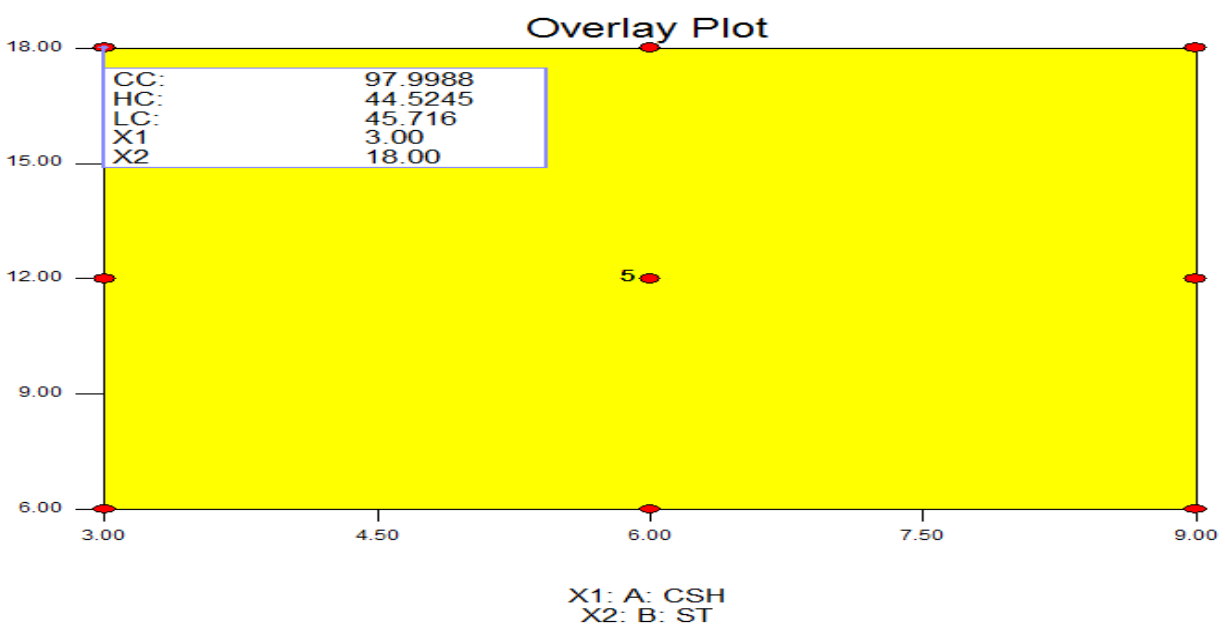

FIGURE 6. The overlay plot for the percentage improvement of $\mathrm{CC}, \mathrm{HC}$, and $\mathrm{LC}$ removal of modified SBBWF.

TABLE 3. Comparison of the predicted results by RSM and experiment values of CC, HC and LC of treated SBBWF at optimum condition

\begin{tabular}{lccccc}
\hline SBBWF compositional & CST & ST & \multicolumn{2}{c}{ Prediction/experiment } & Error difference \\
\cline { 2 - 6 } content & $\%$ & h & $\%$ & $\%$ & $\%$ \\
\hline CC & 3 & 18 & 97.99859 & 97.6924 & 0.313428 \\
HC & 3 & 18 & 44.52456 & 44.3379 & 0.420988 \\
LC & 3 & 18 & 45.71598 & 45.5817 & 0.294586 \\
\hline
\end{tabular}

\section{References}

1. Bouafif H, Koubaa A, Perré P, Cloutier A. Effects of Fibre Characteristics on the Physical and Mechanical Properties of Wood Plastic Composites. The $9^{\text {th }}$ international conference on flow processes in composite materials. 2008, 1-9.

2. Bouafif H, Koubaa A, Perré P, Cloutier A. Effects of fiber characteristics on the physical and mechanical properties of wood plastic composites. Composites Part A: Applied Science and Manufacturing. 2009; 40(12), 1975-1981.

3. Bhandari NL, Thomas S, Das CK, Adhikari R. Analysis of morphological and mechanical behaviors of bamboo flour reinforced polypropylene composites. Nepal Journal of Science and Technology. 2013; 13(1), 95-100.

4. Catto AL, Santana RMC. Influence of coupling agent in polyolefinic composites from postconsumer waste with Eucalyptus grandis flour. Journal of Materials Science and Engineering B. 2018; 3(10), 641-652.

5. Atuanya CU, Government MR, Nwobi-Okoye CC, Onukwuli OD. Predicting the mechanical properties of date palm wood fibre-recycled low density polyethylene composite using artificial neural network. International Journal of Mechanical and Materials Engineering. 2014; 9(1), $1-20$. 
6. Government RM, Onukwuli OD, Ani AK. Chemically treated avocado wood flour-LLDPE composite. USAK University Journal of Material Sciences. 2018; 6(1-2), 27-40.

7. Yang HS, Kim HJ, Son J, Park HJ, Lee BJ, Hwang TS. Rice-husk flour filled polypropylene composites; mechanical and morphological study. Composite Structures. 2004; 63(3-4), 305-312.

8. Kim I, Han JI. Optimization of alkaline pretreatment conditions for enhancing glucose yield of rice straw by response surface methodology. Biomass and Bioenergy. 2012; 46, 210-217.

9. Obasi HC. Peanut husk filled polyethylene composites: effects of filler content and compatibilizer on properties. Journal of Polymers. 2015, 1-9.

10. Rabboni MG, Agu OS, Olowokere JA. The use of flame of forest pod flour in high density polyethylene composite. ACTA Technica Corvinensis-Bulletin of Engineering. 2019; 12, 11-14.

11. Matsunaga T, Sato Y, Goda K. Major cause of strength improvement of a ramie/PA composite with low fiber contents. Advanced Industrial and Engineering Polymer Research. 2018; 1(1), 93-98.

12. Dungani R, Karina M, Subyakto, Sulaeman A, Hermawan D, Hadiyane A. Agricultural waste fibers towards sustainability and advanced utilization: a review. Asian Journal of Plant Sciences. 2016; 15(1-2), 42-55.

13. Prachayawarakorn J, Yaembunying N. Effect of recycling on properties of rice husk-filledpolypropylene. Songklanakarin Journal of Science and Technology. 2005; 27(2), 343-352.

14. Development of new composites of recycled polypropylene and combinations of organic fillers and fibres for the manufacture of fish farming cage. https://www.yumpu.com/en/document/ view/6101038/development-of-new-composites-of-recycled-polypropylene-and. Date accessed: 2018.

15. Kängsepp K, Poltimäe T, Liimand K, Kallakas H, Süld TM, Repeshova I. The effect of wood flour fraction size on the properties of wood-plastic composites. Proceedings of the international conference of DAAAM Baltic 'Industrial Engineering', 2014, 366-371.

16. Nimmagadda VK, Sarcar MMM, Koona R. Investigation of dielectric properties of industrial waste reinforced particulate polymer composites. Advances in Materials Science and Engineering. 2014, 1-6.

17. Harun S, Geok SK. Effect of sodium hydroxide pretreatment on rice straw composition. Indian Journal of Science and Technology. 2016; 9(21), 1-9.

18. Sn W. Sugarcane bagasse: how easy is it to measure its constituents? Proceedings of South African Sugarcane Technology Association. 2008; 81, 266-273.

19. Suryanto H, Marsyahyo E, Irawan YS, Soenoko R. Effect of alkali treatment on crystalline structure of cellulose fiber from Mendong (Fimbristylis globulosa) straw. Key Engineering Materials. 2013; 594-595, 720-724.

20. Hidalgo-Reyes M, Caballero-Caballero M, HernáNdez-Gómez LH, Urriolagoitia-Calderón G. Chemical and morphological characterization of Agave angustifolia bagasse fibers. Botanical Sciences. 2015; 93(4), 807-817.

21. Reddy KO, Reddy KRN, Zhang J, Zhang J, Varada Rajulu A. Effect of alkali treatment on the properties of century fiber. Journal of Natural Fibers. 2013; 10(3), 282-296.

22. Government R, Olowokere J, Odineze C, Anidobu C, Yerima E, Nnaemeka B. Influence of soaking time and sodium hydroxide concentration on the chemical composition of treated mango seed shell flour for composite application. Journal of Applied Sciences and Environmental Management. 2019; 23(1), 21.

23. Yakubu A, Olatunji GA, Mohammed C. Acetylation of wood flour from four wood species grown in Nigeria using vinegar and acetic anhydride. Academic Journal of Interdisciplinary Studies. 2013; 2(10), 147-154. 
24. Barlianti V, Dahnum D, Hendarsyah H, Abimanyu H. Effect of Alkaline pretreatment on properties of lignocellulosic oil palm waste. Procedia Chemistry. 2015; 16, 195-201.

25. Oushabi A, Sair S, Oudrhiri Hassani F, Abboud Y, Tanane O, El Bouari A. The effect of alkali treatment on mechanical, morphological and thermal properties of date palm fibers (DPFs): study of the interface of DPF-polyurethane composite. South African Journal of Chemical Engineering. 2017; 23, 116-123.

26. Chen Y, Tshabalala MA, Gao J, Stark NM, Fan Y, Ibach RE. Thermal behavior of extracted and delignified pine wood flour. Thermochimica Acta. 2014; 591, 40-44.

27. Setswalo K, Namoshe M, Kutua S, Oladijo OP, Samson B. Effect of thermal \& alkali treatment on Pterocarpus angolensis (Mukwa) wood flour. Procedia Manufacturing. 2017; 7, 205-210.

28. Lazic BD, Janjic SD, Rijavec T, Kostic MM. Effect of chemical treatments on the chemical composition and properties of flax fibers. Journal of the Serbian Chemical Society. 2017; 82(1), 83-97.

29. Vardhini KJV, Murugan R, Selvi CT, Surjit R. Optimisation of alkali treatment of banana fibres on lignin removal. Indian Journal of Fibre and Textile Research. 2016; 41(2), 156-160.

30. Palamae S, Dechatiwongse P, Choorit W, Chisti Y, Prasertsan P. Cellulose and hemicellulose recovery from oil palm empty fruit bunch $(\mathrm{EFB})$ fibers and production of sugars from the fibers. Carbohydrate Polymers. 2017; 155, 491-497.

31. Muryanto, Triwahyuni E, Abimayu H, Cahyono A, Cahyono ET, Sudiyani Y. Alkaline delignification of oil palm empty fruit bunch using black liquor from pretreatment. Procedia Chemistry. 2015; 16, 99-105.

32. Sari NH, Wardana ING, Irawan YS, Siswanto E. The effect of sodium hydroxide on chemical and mechanical properties of corn husk fiber. Oriental Journal of Chemistry. 2017; 33(6), 3037-3042.

33. Lazim Y, Salit SM, Zainudin ES, Mustapha M, Jawaid M. Effect of alkali treatment on the physical, mechanical, and morphological properties of waste betel nut (Areca catechu) husk fibre. Bio Resources. 2014; 9(4), 7721-7736.

34. Shi Z, Yang Q, Cai J, Kuga S, Matsumoto Y. Effects of lignin and hemicellulose contents on dissolution of wood pulp in aqueous $\mathrm{NaOH}$ /urea solution. Cellulose. 2014; 21(3), 1205-1215.

35. Ahmadi F, Zamiri MJ, Khorvash M, Ziaee E, Polikarpov I. Pre-treatment of sugarcane bagasse with a combination of sodium hydroxide and lime for improving the ruminal degradability: optimization of process parameters using response surface methodology. Journal of Applied Animal Research. 2016; 44(1), 287-296.

36. Ikramullah, Rizal S, Thalib S, Huzni S. Hemicellulose and lignin removal on typha fiber by alkali treatment. IOP Conference Series: Materials Science and Engineering. 2018; 352(1), 1-7.

37. Wang Z, Li J, Barford JP, Hellgradt K, Mckay G. A comparison of chemical treatment methods for the preparation of rice husk cellulosic fibers. International Journal of Environmental \& Agriculture Research. 2016; 2(1), 67-77.

38. Mahyati, Patong AR, Djide MN, Taba DP, Rauf Patong A, Nasir Djide M. Biodegradation of lignin from corn cob by using a mixture of Phanerochaete chrysosporium, Lentinus edodes and Pleurotus ostreatus. International Journal of Scientific \& Technology. 2013; 2(11), 79-82.

39. Ikhlef S, Nekkaa S, Guessoum M, Haddaoui N. Effects of alkaline treatment on the mechanical and rheological properties of low-density polyethylene/Spartium junceum flour composites. ISRN Polymer Science. 2012, 1-7.

40. Aimi NN, Anuar H, Manshor MR, Nazri WBW, Sapuan SM. Optimizing the parameters in durian skin fiber reinforced polypropylene composites by response surface methodology. Industrial Crops and Products. 2014; 54, 291-295. 
41. Ashenai Ghasemi F, Ghasemi I, Menbari S, Ayaz M, Ashori A. Optimization of mechanical properties of polypropylene/talc/graphene composites using response surface methodology. Polymer Testing. 2016; 53, 283-292.

42. Güllü H, Fedakar Hİ. Response surface methodology for optimization of stabilizer dosage rates of marginal sand stabilized with sludge ash and fiber based on UCS performances. KSCE Journal of Civil Engineering. 2017; 21(5), 1717-1727.

43. Kandar MIM, Akil HM. Application of design of experiment (DoE) for Parameters optimization in compression moulding for flax reinforced biocomposites. Procedia Chemistry. 2016; 19, 433-440.

44. Sun Y, Liu J, Kennedy JF. Application of response surface methodology for optimization of polysaccharides production parameters from the roots of Codonopsis pilosula by a central composite design. Carbohydrate Polymers. 2010; 80(3), 949-953.

45. Angellier H, Choisnard L, Molina-Boisseau S, Ozil P, Dufresne A. Optimization of the preparation of aqueous suspensions of waxy maize starch nanocrystals using a response surface methodology. Biomacromolecules. 2004; 5(4), 1545-1551.

46. Masmoudi M, Besbes S, Chaabouni M, Robert C, Paquot M, Blecker C. Optimization of pectin extraction from lemon by-product with acidified date juice using response surface methodology. Carbohydrate Polymers. 2008; 74(2), 185-192.

47. Cotana F, Barbanera M, Foschini D, Lascaro E, Buratti C. Preliminary optimization of alkaline pretreatment for ethanol production from vineyard pruning. Energy Procedia. 2015; 82, 389-394.

48. Sun R, Lawther JM, Banks WB. Influence of alkaline pre-treatments on the cell wall components of wheat straw. Industrial Crops and Products. 1995; 4(2), 127-145.

49. Shi S, Liang J. Thermal decomposition behavior of silica-phenolic composite exposed to onesided radiant heating. Polymers and Polymer Composites. 2008, 16(2), 101-113.

50. Ma'Ruf A, Pramudono B, Aryanti N. Lignin isolation process from rice husk by alkaline hydrogen peroxide: Lignin and silica extracted. AIP Conference Proceedings. 2017; 1823, 2-7.

51. Influence of lignin accessibility on chemical and biological decomposition of lignin/polyethylene composite thermoplastics. https://onlinelibrary.wiley.com/doi/abs/10.1002/cjce.23623. Date accessed: 14/08/2018. 